HIAS-E-106

\title{
Trade, Consumption Pollution and Tax
}

\author{
Haitao Cheng (a) \\ (a) Hitotsubashi Institute for Advanced Study, Hitotsubashi University \\ This version: April 2021 \\ First version: October 2018
}

Institute for

Hitotsubashi Institute for Advanced Study, Hitotsubashi University

2-1, Naka, Kunitachi, Tokyo 186-8601, Japan

tel:+81 425808668 http://hias.hit-u.ac.jp/

HIAS discussion papers can be downloaded without charge from: https://hdl.handle.net/10086/27202

https://ideas.repec.org/s/hit/hiasdp.html

All rights reserved. 


\title{
Trade, Consumption Pollution and Tax ${ }^{\star}$
}

\author{
Haitao Cheng \\ Hitotsubashi Institute for Advanced Study, Hitotsubashi University
}

This version: April 2021

First version: October 2018

\begin{abstract}
Consumption is an important source of greenhouse gas (GHG) emissions. This study theoretically analyzes how trade liberalization and consumption tax affect firm locations across countries and GHG emissions originating from consumption. Introducing consumption-originated emissions in a standard footloose capital model, we find several novel results that extend previous analyses of production-originated GHG emissions. First, trade liberalization has a non-monotonic effect on global emissions; that is, as trade costs decline, global emissions initially decrease and then increase. Second, consumption taxes cause carbon leakage; that is, the tax on one country reduces emissions in that country, while increasing it in the rest of the world. Third, optimal consumption taxes that maximize global welfare must be neutral about firm location decisions. In particular, even if firms are asymmetrically distributed across countries in the absence of a consumption tax, the optimal tax level must be identical across countries.

Keywords: Asymmetric market sizes; Consumption pollution; Consumption tax harmonization; Footloose capital model; Trade liberalization

JEL classification: F18; Q54; Q58
\end{abstract}

${ }^{\star}$ I am deeply indebted to Professors Jota Ishikawa and Yoichi Sugita for their valuable comments and constant encouragement. I would like to thank Professors Hayato Kato, James Markusen, Hirofumi Okoshi, Hajime Takatsuka, Kensuke Teshima, Eiichi Tomiura and Dao-Zhi Zeng for helpful suggestions. Thanks also go to the participants at the 78th Annual Meeting of the JSIE, IEFS Japan Annual Meetings 2019 (Poster Session) and 2020 and seminars at Hitotsubashi University. Financial support from Hitotsubashi Institute for Advanced Study is gratefully acknowledged. All remaining errors are my own. E-mail address: haitaoecon@gmail.com. 


\section{Introduction}

Previous research on trade and the environment strongly focuses on emissions from the production side; however, less attention is paid to the consumption side. ${ }^{1}$ Consumption is an important source of greenhouse gas (GHG) emissions such as fossil fuel combustion for cooking, heating, and transportation, and it also leaks from refrigerants in businesses and homes. According to the US Environmental Protection Agency, direct GHG emissions from residents and businesses, excluding agricultural and industrial activities, accounted for 11.6 percent of US GHG emissions in 2017. This proportion is even larger in Japan; the Japanese Ministry of the Environment announced that the commercial and residential sectors generated 33.4 percent of Japanese $\mathrm{CO}_{2}$ emissions in 2016 .

GHG emissions from the production and consumption sides should be distinguished. Production emissions occur when dirty goods are produced, while consumption emissions occur when they are consumed. Owing to this difference, the behaviors of consumers, firms, and countries can also differ in the presence of environmental regulations. For instance, if a country becomes a periphery with no firms, its domestic environmental regulation no longer affects production emissions because of the lack of production there. However, it still affects consumption emissions as long as residents consume imported goods.

Against this background, we investigate the environmental issues of consumption in this study. Specifically, we examine how trade liberalization and environmental taxes affect GHG emissions as well as how heterogeneous countries choose their tax levels cooperatively and non-cooperatively. To do so, we employ the footloose capital model of Martin and Rogers (1995), which emphasizes the diversity of goods and endogenous firm locations, key features in today's trade liberalization. To conduct the policy analysis, we assume an ad valorem consumption tax on consumers as an (indirect) environmental instrument. Changing the consumption tax to an emission tax has no impact on our main conclusions; however, the tractability and feasibility of the analysis diminishes. An example of a consumption tax functioning as an environmental regulation is the tax on the consumption of fossil fuels. Several governments such as those in Norway and the United Kingdom impose a fuel tax - a type of ecotax - to control $\mathrm{CO}_{2}$ emissions from vehicles. We consider not only developed countries but also developing countries, as both are obliged to control GHG emissions under the Paris Agreement.

To analyze how trade liberalization and consumption taxes affect GHG emissions, we decompose the total effect into a firm relocation effect and a demand effect. The firm relocation effect describes

\footnotetext{
${ }^{1}$ Examples of studies dealing with production pollution are Markusen et al. (1993, 1995) and Copeland and Taylor (1994, 1995b). Compared with the little attention paid to consumption emissions in the theoretical literature, the empirical literature is extensive, including Druckman et al. (2008), Wiedmann (2009), and Davis and Caldeira (2010).
} 
the changes in GHG emissions due to the relocation of firms. This differs from the composition effect - discussed in previous research - that measures the reallocation of production factors across relatively clean and dirty goods. The net firm relocation effect is always neutral in the model. The demand effect captures the changes in GHG emissions due to the changes in the consumption of dirty goods.

Given a consumption tax, as trade costs decline, the demand effect tends to initially decrease global emissions and then increase them. We can understand the intuition behind this non-monotonicity as follows. The consumption of dirty goods under free trade is equal to that under autarky because there are no trade costs in either case. However, under trade with costs, consumers have to pay extra trade costs, which decreases consumption globally. Hence, GHG emissions are lower than in the two extreme cases. The literature has not reached a consensus on how trade affects the environment. Previous theoretical analyses with neoclassical settings show that free trade can increase world pollution (e.g., Copeland and Taylor, 1994, 1995b). On the contrary, Antweiler et al. (2001) empirically find that openness to the international goods market appears to be good for the environment because trade increases income and induces the development of cleaner production technology. Our findings suggest an alternative answer to this question through the substitution between variety and quantity. Trade may reduce world consumption and pollution by increasing the variety of consumption goods.

Given trade costs, as the consumption tax increases in either country, local emissions decrease in that country and increase in the other country; global emissions always decline because the demand effect is always negative. Many studies have examined carbon leakage under production emissions, claiming that a more stringent environmental regulation in a country increases other countries' production emissions (e.g., Markusen et al., 1993, 1995). Our findings indicate that carbon leakage still exists under consumption pollution. Intuitively, an increase in the consumption tax in a country decreases its consumption and thus its emissions from consumption. However, it is not straightforward why consumption emissions in the other country increase.

In the welfare analysis, we first focus on the global optimum to determine what countries should do cooperatively. The analysis shows how a supranational regime designs an environmental tax to control GHG emissions. We find that optimal consumption taxes must be neutral to firm location decisions. In particular, if firms initially disperse across countries under no environmental regulation, identical consumption taxes are globally desirable regardless of market size. This finding is related to the literature on environmental tax harmonization, which seeks to construct a simple policy to deal with complicated environmental problems, especially in the presence of heterogeneous countries (e.g., Vlassis, 2013; Cremer and Gahvari, 2004; Cheng et al., 2020). Among others, Cheng et al. (2020) examine whether environmental tax harmonization is globally desirable in global value 
chains given that countries differ in their average cost advantages of input production. They find that environmental tax harmonization is socially optimal when unbundling costs are high, but not when unbundling costs are low. Compared with theirs, our findings do not depend on the levels of trade costs; moreover, the model has different production processes, market structures, environmental issues, and country heterogeneity.

Under consumption tax competition, we investigate how countries choose their taxes in the presence of endogenous firm locations and how market sizes affect their decisions. We show that a Nash equilibrium may exist in which firms disperse across countries and that the consumption tax is always higher in the larger country. The analysis is related to the literature on environmental tax competition in the presence of imperfect competition and endogenous firm locations (e.g., Markusen et al., 1995; Rauscher, 1995; Hoel, 1997; Dong et al., 2012). Markusen et al. (1995) and Hoel (1997) claim that optimal environmental taxes at the Nash equilibrium depend on the marginal environmental damage, which is also revealed in our results. Dong et al. (2012) show that countries' choices are relevant to their market sizes, which are assumed to be identical. In contrast to their analyses, we emphasize the asymmetry of market size.

\subsection{Related Literature}

This study follows the literature on new economic geography and the environment. Examples include Zeng and Zhao (2009) and Ishikawa and Okubo (2011, 2016, 2017). The basic setup in this study is close to that of Ishikawa and Okubo $(2011) .^{2}$ However, they only analyze unilateral environmental product standards and do not look further through a welfare analysis. By contrast, we investigate bilateral consumption taxes in both countries and derive the global and national optima. The examination of how consumption taxes affect firm behaviors and GHG emissions is similar to the analysis of full border tax adjustments by Ishikawa and Okubo (2017) in that environmental regulation appears in the consumption country. However, they compare unilateral emission quotas with emission taxes in the presence of GHG emissions from production and derive the neutral effect of border tax adjustments on firm locations, which is different from the findings of this study.

Ishikawa and Okubo (2016) also find a non-monotonic effect of trade liberalization on GHG emissions in a model in which emissions originate from production. Our mechanism differs from theirs. First, in their model, trade liberalization affects global emissions only when the emission tax is strictly positive; if the tax rate is zero, global emissions are independent of trade costs.

\footnotetext{
${ }^{2}$ The other three papers cited here all focus on production pollution. Zeng and Zhao (2009) investigate the effect of production pollution on agricultural productivity, while Ishikawa and Okubo $(2016,2017)$ investigate the effect of production pollution on residents.
} 
However, our results hold even without an environmental tax. Second, if our model is modified so that emissions originate from production instead of consumption, trade liberalization has no effect on global emissions. Therefore, the distinction between consumption and production emissions is important.

However, few studies have examined trade and consumption pollution (e.g., Krutilla, 1991; Copeland and Taylor, 1995a; Ishikawa and Kuroda, 2007; Ishikawa and Okubo, 2010, 2011; Hu and McKitrick, 2016). Krutilla (1991) derives a series of second-best consumption taxes with the existence of production and consumption pollution and concludes that environmental production and consumption taxes affect the world price and trade balance in opposite directions. Ishikawa and Kuroda (2007) and Ishikawa and Okubo (2010) examine and compare the effectiveness of various taxes in reducing emissions from production and/or consumption. They find that emission taxes may be less effective at decreasing consumption emissions than other taxes such as production taxes and tariffs. Hu and McKitrick (2016) compare production and consumption pollution with a model similar to that of Antweiler et al. (2001) and find that trade liberalization affects the two kinds of pollution differently through trade-induced composition effects. Copeland and Taylor (1995a) employ a Heckscher-Ohlin model and verify that the dirty industry migration hypothesis holds in the presence of local consumption pollution. Compared with their findings, we demonstrate that whether firms migrate to countries with laxer environmental regulations also depends on market size. Except for Ishikawa and Okubo (2011), the studies mentioned in this strand consider neither endogenous firm locations nor monopolistic competition.

This study also complements the literature on conventional trade policy competition and coordination (e.g., Ludema and Wooton, 2000; Baldwin and Krugman, 2004; Haufler and Wooton, 2010; Haufler and Pflüger, 2004). The basic setup of this study is similar to the tax regime based on the destination principle in Haufler and Pflüger (2004). However, they do not consider asymmetric market sizes, the full agglomeration of firms, or environmental issues. With consumption externalities, governments consider not only the consumer surplus and tax revenue, but also environmental damage. If environmental damage is large, governments are likely to impose stringent environmental regulations (or lower consumption subsidies), even though this harms the consumer surplus.

The remainder of this paper is organized as follows. Section 2 introduces the basic model setup. Section 3 derives the equilibrium in trade with footloose capital and investigates how trade liberalization and consumption taxes affect firm locations, consumption, and GHG emissions. Section 4 discusses the global optimum. Section 5 discusses consumption tax competition. Finally, Section 6 concludes. 


\section{Basic Model}

The basic model extends the footloose capital model of Martin and Rogers (1995) by including the GHG emissions from consumption and consumption taxes. Consider a world with two countries, Home and Foreign, and two factors, capital and labor. The individuals in each country consume two types of goods: a dirty manufacturing good with different varieties and a clean agricultural good. Each firm produces a variety of dirty goods at a fixed cost of one unit of capital; in addition, one unit of dirty goods requires one unit of labor. ${ }^{3}$ Dirty goods are traded with symmetric trade costs $\tau$ of the "iceberg" form such that $\tau$ units of dirty goods are traded for one unit that is eventually consumed. The clean good is the numéraire. It is homogeneous and freely tradable. The production of clean goods is subject to constant returns to scale and each unit is produced with only one unit of labor. The wage rates across countries are equalized because of the existence of the numéraire, and they are normalized to 1 for simplicity. Denote the labor and capital stock in Home as $L$ and $K$ and those in Foreign as $L^{*}$ and $K^{*}$, respectively. ${ }^{4}$ The two production factors are distributed proportionately across countries and capital is distributed uniformly across the residents within each country. Denote $s$ as the share of the world's labor and capital belonging to Home, that is, $L /\left(L+L^{*}\right)=K /\left(K+K^{*}\right)=s$. Without loss of generality, total capital and labor are both normalized to unity; Home is assumed to have a larger market size $(s>1 / 2)$. Labor is immobile across countries, but can freely move across sectors and firms. Capital is mobile across countries and capital rents are paid to local owners. GHG emissions are generated during the consumption of dirty goods, with one unit of dirty goods emitting one unit of GHG. Governments impose ad valorem consumption taxes on consumers to control GHG emissions under the requirements of environmental agreements such as the Paris Agreement.

The utility of a representative individual in Home is described as a quasi-linear function:

$$
U=\mu \ln M+A-D\left(E^{G}\right)
$$

where

$$
M \equiv\left(n x^{H H^{1-\frac{1}{\sigma}}}+n^{*} x^{F H^{1-\frac{1}{\sigma}}}\right)^{\frac{\sigma}{\sigma-1}}
$$

is the constant elasticity of substitution composite consumption of the dirty manufacturing varieties and $A$ is the consumption of the numéraire. $D(\cdot)$ is the environmental damage function that measures the disutility of emissions. $E^{G}$ represents the global emission level. $n$ is the number (or ratio) of differentiated varieties in Home and $n^{*}$ is that in Foreign. $x^{H H}$ denotes the quantity of

\footnotetext{
${ }^{3}$ The term "firm" only refers to the producer of dirty goods throughout the paper.

${ }^{4}$ Variables with asterisks are Foreign-related.
} 
Home consumption of each variety produced by Home and $x^{F H}$ is the counterpart produced by Foreign. The first capital letter in the superscripts represents the location of production and the second represents the location of consumption. $\sigma>1$ is the constant elasticity of substitution between the different varieties, as is usually observed in the constant elasticity of substitution function. $\mu$ is the intensity of preference for good $M$. The larger the value of $\mu$, the more the individual spends on dirty goods.

The budget constraint of the representative individual in Home is

$$
n p(1+t) x^{H H}+n^{*} \tau p^{*}(1+t) x^{F H}+A=I / L
$$

$I=L+r K+T R$ denotes total income, where $r$ is the capital rent in Home, $T R=L t\left(n p x^{H H}+n^{*} \tau p^{*} x^{F H}\right)$ is total tax revenue, and $t$ represents the Home ad valorem consumption tax. The term $x^{F H}$, but not $x^{H F}$, enters total tax revenue because the consumption tax is imposed on consumers but not producers. $p$ and $p^{*}$ are the pre-trade prices of dirty goods in each country and $\tau p^{*}$ is the import price of Foreign dirty goods in Home, adjusted by trade costs. Similarly, the utility function and corresponding variables for Foreign can be derived. For simplicity, $\mu$ and $\sigma$ are assumed to be the same across countries.

The aggregate price index facing the individual in Home is

$$
P=(1+t)\left[n p^{1-\sigma}+n^{*}\left(\tau p^{*}\right)^{1-\sigma}\right]^{\frac{1}{1-\sigma}} .
$$

Unlike a tax on producers, a country's consumption tax cannot directly affect the aggregate price in the other country. However, an indirect channel still exists through the effect of the consumption tax on firm locations. On the contrary, trade liberalization can affect the aggregate prices in the two countries both directly and indirectly.

The consumption of each Home- and Foreign-produced variety in Home and Foreign is

$$
\begin{gathered}
x^{H H}=\mu P^{\sigma-1}[p(1+t)]^{-\sigma} ; \quad x^{F H}=\mu P^{\sigma-1}\left[\tau p^{*}(1+t)\right]^{-\sigma} ; \\
x^{F F}=\mu P^{* \sigma-1}\left[p^{*}\left(1+t^{*}\right)\right]^{-\sigma} ; x^{H F}=\mu P^{* \sigma-1}\left[\tau p\left(1+t^{*}\right)\right]^{-\sigma} .
\end{gathered}
$$

For a representative firm in Home and Foreign, if any, its capital rent is

$$
r=(p-1) Y ; \quad r^{*}=\left(p^{*}-1\right) Y^{*}
$$

where

$$
Y=s x^{H H}+(1-s) \tau x^{H F} ; \quad Y^{*}=s \tau x^{F H}+(1-s) x^{F F}
$$


are the total production of each variety. The markup pricing rule of the Dixit-Stiglitz monopolistic competition model in Dixit and Stiglitz (1977) still holds and the identical pre-tax prices across varieties are derived as

$$
p=p^{*}=\sigma /(\sigma-1) .
$$

\section{Trade Equilibrium}

In this section, we derive the trade equilibrium and examine how trade costs and consumption taxes affect firm locations, consumption, and emissions. At the trade equilibrium, there are two possible cases. In the first case, firms disperse across countries; in the second case, the full agglomeration of firms occurs in one country.

If the difference between consumption taxes is moderate, firms disperse across countries, that is, $s \tau^{1-\sigma} /(1-s)<(1+t) /\left(1+t^{*}\right)<s \tau^{\sigma-1} /(1-s)$. The difference between capital rents in the two countries is

$$
\begin{aligned}
\Delta r=r-r^{*} & =(p-1) Y-\left(p^{*}-1\right) Y^{*}=\left(Y-Y^{*}\right) /(\sigma-1) \\
& =\mu\left(\tau^{\sigma}-\tau\right)\left[\frac{s}{(1+t)\left(n \tau^{\sigma}+n^{*} \tau\right)}-\frac{1-s}{\left(1+t^{*}\right)\left(n \tau+n^{*} \tau^{\sigma}\right)}\right]
\end{aligned}
$$

At the trade equilibrium, no arbitrage exists because capital is footloose across countries. Therefore, capital rents are the same $\left(r=r^{*}\right)$, which in turn equalizes the total production of each variety $\left(Y=Y^{*}\right)$.

Along with the condition that $n+n^{*}=K+K^{*}=1$, the number of firms (or varieties) in Home and Foreign is derived as

$$
n=\frac{1}{\tau^{\sigma-1}-1} \frac{s\left(1+t^{*}\right) \tau^{\sigma-1}-(1-s)(1+t)}{s\left(1+t^{*}\right)+(1-s)(1+t)} ; n^{*}=1-n .
$$

Lemma 1. Suppose firms disperse across countries.

( $i$ ) An increase in a country's consumption tax induces firms to relocate to the other country, i.e., $\mathrm{d} n / \mathrm{d} t<0, \mathrm{~d} n^{*} / \mathrm{d} t^{*}<0$.

(ii) How trade liberalization affects firm locations depends on the strengths between the market sizes and consumption taxes, i.e.,

$$
\frac{\mathrm{d} n}{\mathrm{~d} \tau}=\frac{(\sigma-1) \tau^{\sigma-2}(1+t)\left(1+t^{*}\right)}{\left(\tau^{\sigma-1}-1\right)^{2}\left[s\left(1+t^{*}\right)+(1-s)(1+t)\right]}\left(\frac{1-s}{1+t^{*}}-\frac{s}{1+t}\right) .
$$


To understand the intuitions behind the findings, we first investigate how the number of firms and consumption tax affect the capital rent difference in equation (10). First, as more firms are located in Home, the Home market becomes more competitive, lowering the capital rents of each firm $(\partial \Delta r / \partial n<0)$. Second, as the consumption tax in Home increases, residents consume fewer of each variety of dirty goods and capital rents in both Home and Foreign decrease; however, firms suffer more in Home because residents in Home consume more of each Home variety, which makes Foreign more attractive $(\partial \Delta r / \partial t<0)$. At the trade equilibrium, $\Delta r=0$. In Lemma 1- $(i)$, as $t$ increases, capital rents in Foreign become relatively high and firms relocate from Home to Foreign until the capital rents are equalized again. In Lemma 1- $(i i)$, if there are no consumption taxes, our model collapses to the conventional footloose capital model. Firms locate in the larger country more than proportionately and trade liberalization strengthens this tendency until firms fully agglomerate in the larger country, that is, $\partial \Delta r /\left.\partial \tau\right|_{t=t^{*}=0}<0, \partial \Delta r /\left.\partial n\right|_{t=t^{*}=0}<0, \mathrm{~d} n /\left.\mathrm{d} \tau\right|_{t=t^{*}=0}<0$. However, the relationship between trade liberalization and the capital rent difference is ambiguous in the presence of consumption taxes because they play a role in shrinking the market. Therefore, how trade liberalization affects firm locations depends on the extent to which the consumption tax shrinks the market. Suppose $t>t^{*}$. If $t$ is sufficiently high that $(1-s) /\left(1+t^{*}\right)>s /(1+t)$, firms relocate to Foreign under trade liberalization because the effective market size is larger in Foreign. If $t$ is not so high that $(1-s) /\left(1+t^{*}\right)<s /(1+t)$, trade liberalization induces firms to relocate to Home, which has a higher consumption tax. If $t$ fully offsets Home's market size advantage, that is, $(1-s) /\left(1+t^{*}\right)=s /(1+t)$, trade liberalization has no effect on firm locations, which is the same as the case of symmetric market sizes in the conventional footloose capital model.

The levels of each type of consumption are

$$
\begin{aligned}
& x^{H H}=\frac{\mu(\sigma-1)}{\sigma} \frac{\tau^{\sigma}}{\tau^{\sigma}+\tau}\left(\frac{1}{1+t}+\frac{1-s}{s} \frac{1}{1+t^{*}}\right) ; \quad x^{F H}=\frac{x^{H H}}{\tau^{\sigma}} ; \\
& x^{F F}=\frac{\mu(\sigma-1)}{\sigma} \frac{\tau^{\sigma}}{\tau^{\sigma}+\tau}\left(\frac{1}{1+t^{*}}+\frac{s}{1-s} \frac{1}{1+t}\right) ; \quad x^{H F}=\frac{x^{F F}}{\tau^{\sigma}} .
\end{aligned}
$$

Lemma 2. When firms disperse across countries,

(i) $x^{H H}>x^{F H}, x^{F F}>x^{H F}$;

(ii) $\frac{\mathrm{d} x^{H H}}{\mathrm{~d} \tau}>0, \frac{\mathrm{d} x^{F H}}{\mathrm{~d} \tau}<0, \frac{\mathrm{d} x^{F F}}{\mathrm{~d} \tau}>0, \frac{\mathrm{d} x^{H F}}{\mathrm{~d} \tau}<0$;

(iii) $\frac{\mathrm{d} x^{i j}}{\mathrm{~d} t}<0, \frac{\mathrm{d} x^{i j}}{\mathrm{~d} t^{*}}<0$, where $i, j=H, F$.

The consumption of each domestic variety of dirty goods is always larger than that of each imported variety because of the existence of trade costs. Trade liberalization raises the consumption 
of each imported variety and decreases that of each domestic variety because the imported varieties become relatively cheap as trade costs decline. In addition, an increase in the consumption tax of either country always reduces the consumption of all varieties of dirty goods. Suppose that $t$ increases; then, the after-tax price of each variety of dirty goods increases in Home. Therefore, $x^{H H}$ and $x^{F H}$ decrease. Moreover, an increase in $t$ lowers $P^{*}$, which in turn decreases $x^{F F}$ and $x^{H F}$, as shown in equation (6).

Each country's emissions are the sum of the emissions from the dirty goods consumed in a country and global emissions are the sum of the emissions from the two countries:

$$
E=n s x^{H H}+n^{*} s x^{F H} ; \quad E^{*}=n(1-s) x^{H F}+n^{*}(1-s) x^{F F} ; \quad E^{G}=E+E^{*} .
$$

In the following part, we show how trade liberalization affects global emissions.

Proposition 1. The effect of trade liberalization on global emissions can be non-monotonic. As trade costs decline, global emissions first decrease and then increase.

The impact of trade liberalization on global emissions can be decomposed into the firm relocation and demand effects. The firm relocation effect measures the impact of firm relocation, as shown in Lemma 1, and the demand effect captures the impact of changes in consumption, as shown in Lemma 2.

$$
\begin{aligned}
& \frac{\mathrm{d} E^{G}}{\mathrm{~d} \tau}=\frac{\mathrm{d} E}{\mathrm{~d} \tau}+\frac{\mathrm{d} E^{*}}{\mathrm{~d} \tau} \\
& =\underbrace{s x^{H H} \frac{\mathrm{d} n}{\mathrm{~d} \tau}+s x^{F H} \frac{\mathrm{d} n^{*}}{\mathrm{~d} \tau}+(1-s) x^{H F} \frac{\mathrm{d} n}{\mathrm{~d} \tau}+(1-s) x^{F F} \frac{\mathrm{d} n^{*}}{\mathrm{~d} \tau}}_{0}+ \\
& \underbrace{n \frac{\mathrm{d} s x^{H H}}{\mathrm{~d} \tau}+n^{*} \frac{\mathrm{d}(1-s) x^{F F}}{\mathrm{~d} \tau}}_{+}+\underbrace{n^{*} \frac{\mathrm{d} s x^{F H}}{\mathrm{~d} \tau}+n \frac{\mathrm{d}(1-s) x^{H F}}{\mathrm{~d} \tau}}_{-} \\
& =\frac{\mu(\sigma-1)}{\sigma}\left(\frac{s}{1+t}+\frac{1-s}{1+t^{*}}\right) \frac{(\sigma-1) \tau^{\sigma}-\sigma \tau^{\sigma-1}-1}{\left(\tau^{\sigma}+\tau\right)^{2}} .
\end{aligned}
$$

The firm relocation effect in each country can be positive, negative, or neutral depending on the relationship between consumption taxes and market size. However, the net firm relocation effect of trade liberalization is always neutral because the consumption of each domestic variety and imported variety is the same separately across countries, that is, $s x^{H H}=(1-s) x^{F F}$ and $s x^{F H}=(1-s) x^{H F}$. A change in emissions in one country caused by firm relocation is offset by the change in emissions in the other country. Thus, how trade liberalization affects global emissions 
is determined by the demand effect of dirty goods. As trade costs decline, the consumption of each imported variety increases and that of each domestic variety decreases. When trade costs are high, the increase in GHG emissions from the consumption of imported goods is dominated by the decrease in the consumption of domestic goods; hence, total emissions tend to decrease. However, when trade costs are low, the case can be reversed and total emissions increase. The non-monotonic effect is likely to occur when $(1+t) /\left(1+t^{*}\right)$ is close to $s /(1-s)$. Otherwise, global emissions continue to decrease until firms fully agglomerate in Home or Foreign.

We now examine how the consumption tax affects GHG emissions. In this section, the consumption tax is exogenous. The endogenous case is described in Sections 4 and 5.

Proposition 2. An increase in the consumption tax in one country reduces the emissions in that country and raises the emissions in the other country. Global emissions always decrease.

Note that

$$
\begin{gathered}
\frac{\mathrm{d} E}{\mathrm{~d} t}=\underbrace{s x^{H H} \frac{\mathrm{d} n}{\mathrm{~d} t}+s x^{F H} \frac{\mathrm{d} n^{*}}{\mathrm{~d} t}}_{-}+\underbrace{n \frac{\mathrm{d} s x^{H H}}{\mathrm{~d} t}+n^{*} \frac{\mathrm{d} s x^{F H}}{\mathrm{~d} t}}_{-}<0 ; \\
\frac{\mathrm{d} E^{*}}{\mathrm{~d} t}=\underbrace{(1-s) x^{H F} \frac{\mathrm{d} n}{\mathrm{~d} t}+(1-s) x^{F F} \frac{\mathrm{d} n^{*}}{\mathrm{~d} t}}_{+}+\underbrace{n \frac{\mathrm{d}(1-s) x^{H F}}{\mathrm{~d} t}+n^{*} \frac{\mathrm{d}(1-s) x^{F F}}{\mathrm{~d} t}}_{-}>0 ; \\
\frac{\mathrm{d} E^{G}}{\mathrm{~d} t}=\frac{\mathrm{d} E}{\mathrm{~d} t}+\frac{\mathrm{d} E^{*}}{\mathrm{~d} t}<0 .
\end{gathered}
$$

The impact of the consumption tax on emissions can also be decomposed into the firm relocation and demand effects. The demand effect is always negative because an increase in the consumption tax decreases demand for both domestic and imported dirty goods. The firm relocation effect is negative in one country and positive in the other country because of the relatively high consumption of domestic goods compared with imported goods. The net firm relocation effect of a consumption tax is also neutral because the total consumption of dirty goods is the same in the two countries. As a result, the total effect of the consumption tax on global emissions is always negative. In addition, the total effect of $t$ on emissions is negative for Home and positive for Foreign, which verifies the existence of carbon leakage under consumption pollution. The intuition behind this finding is as follows. An increase in the Home consumption tax increases the aggregate price index in Home and decreases that in Foreign. Since the expenditure on dirty goods is constant in each country, the total consumption of dirty goods decreases in Home and increases in Foreign, that is, $s \mu / P$ decreases and $(1-s) \mu / P^{*}$ increases.

If the consumption tax in Home is sufficiently smaller than that in Foreign, firms fully ag- 
glomerate in Home to benefit from the larger market and laxer environmental regulations, and vice versa. For $(1+t) /\left(1+t^{*}\right) \leq s \tau^{1-\sigma} /(1-s)$, all firms agglomerate in Home, Foreign specializes in the production of the clean good, and Foreign imports dirty goods from Home. For $(1+t) /\left(1+t^{*}\right) \geq s \tau^{\sigma-1} /(1-s)$, all firms agglomerate in Foreign, Home specializes in the production of the clean good, and Home imports dirty goods from Foreign. Consumption and emissions under full agglomeration are shown in Appendix A1.

\section{Global Optimum}

This section studies how the social planner maximizes global welfare by deciding on the consumption taxes in each country. For simplicity, we make several assumptions. First, we assume that environmental damage is increasing and convex with respect to global emissions, that is, $D^{\prime}\left(E^{G}\right)>0$ and $D^{\prime \prime}\left(E^{G}\right)>0$, following Copeland and Taylor $(1994,1995 b)$. Second, we assume that firms disperse across countries when there is no consumption tax, that is, $s /(1-s)<\tau^{\sigma-1}$. This assumption ensures that the market size across countries is similar or that trade costs are not too low. ${ }^{5}$ Lastly, we define global welfare as the sum of individual utility globally:

$$
W^{G}=s U+(1-s) U^{*}
$$

Suppose that the social planner has no incentive to induce the full agglomeration of firms in a country. The first-order conditions of global welfare concerning $t$ and $t^{*}$ are derived as follows:

$$
\begin{gathered}
\frac{\mathrm{d} W^{G}}{\mathrm{~d} t}=\mu \zeta\left(-1+\phi \zeta-\frac{1}{\sigma-1} \frac{\zeta^{*}}{\zeta+\zeta^{*}}+\frac{1}{\sigma-1} \frac{1-s}{s} \frac{\zeta}{\zeta+\zeta^{*}}\right)=0, \\
\frac{\mathrm{d} W^{G}}{\mathrm{~d} t^{*}}=\mu \zeta^{*}\left(-1+\phi^{*} \zeta-\frac{1}{\sigma-1} \frac{\zeta}{\zeta+\zeta^{*}}+\frac{1}{\sigma-1} \frac{s}{1-s} \frac{\zeta^{*}}{\zeta+\zeta^{*}}\right)=0,
\end{gathered}
$$

where

$$
\begin{gathered}
\zeta=\frac{s}{1+t}, \quad \zeta^{*}=\frac{1-s}{1+t^{*}}, \\
\phi=\frac{1}{s} \frac{\sigma-1}{\sigma}+\frac{1}{s} \frac{\sigma-1}{\sigma} \frac{\tau^{\sigma}+1}{\tau^{\sigma}+\tau} D^{\prime}, \\
\phi^{*}=\frac{1}{1-s} \frac{\sigma-1}{\sigma}+\frac{1}{1-s} \frac{\sigma-1}{\sigma} \frac{\tau^{\sigma}+1}{\tau^{\sigma}+\tau} D^{\prime} .
\end{gathered}
$$

\footnotetext{
${ }^{5}$ In Appendix A3, we study the case in which the firms fully agglomerate in a country initially, that is, $s /(1-s) \geq$ $\tau^{\sigma-1}$. Our main result does not change. That is, optimal consumption taxes that maximize global welfare are neutral about firm location decisions.
} 
Note that $\phi^{*}=\frac{s}{1-s} \phi$. Rearranging the first-order conditions gives

$$
\left(\frac{\zeta}{s}-\frac{\zeta^{*}}{1-s}\right)\left(\frac{1}{\sigma-1}+\phi s\left(\zeta+\zeta^{*}\right)\right)=0
$$

which implies identical consumption taxes

$$
t_{G O}=t_{G O}^{*}
$$

Bringing the identical tax rates into equation (21) shows

$$
\underbrace{1+t_{G O}}_{\text {LHS }}=\underbrace{\frac{\sigma-1}{\sigma}+\frac{\sigma-1}{\sigma} \frac{\tau^{\sigma}+1}{\tau^{\sigma}+\tau} D^{\prime}}_{R H S} .
$$

Under the condition that $D^{\prime \prime}>0$ and $\frac{\mathrm{d} E^{G}}{\mathrm{~d} t}<0, \frac{\mathrm{d} D^{\prime}}{\mathrm{d} t}=\frac{\mathrm{d} D^{\prime}}{\mathrm{d} E^{G}} \frac{\mathrm{d} E^{G}}{\mathrm{~d} t}=D^{\prime \prime} \frac{\mathrm{d} E^{G}}{\mathrm{~d} t}<0$ holds. Thus, the optimal tax rates are determined by the intersection shown in Figure 1.

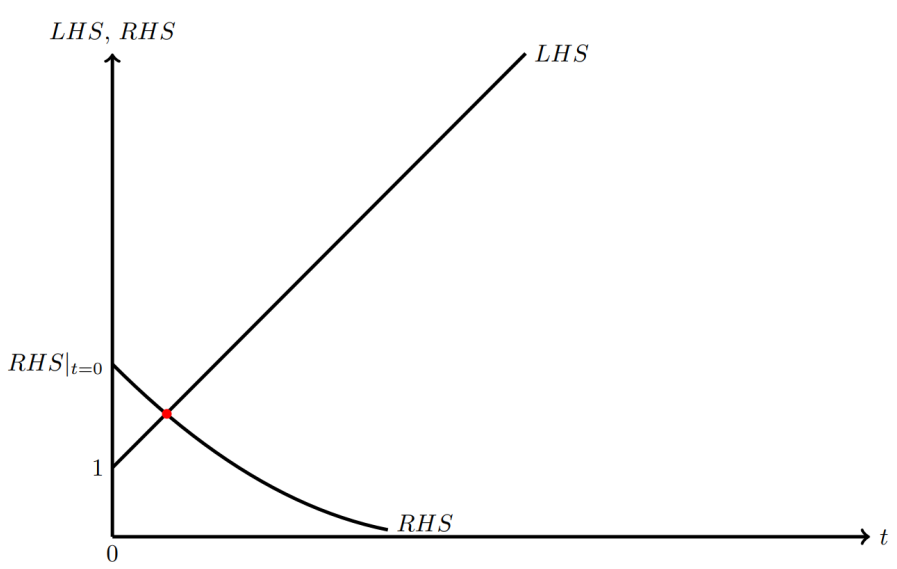

Figure 1: Optimal consumption tax when $\left.R H S\right|_{t=0}>1$.

The optimal consumption taxes are identical regardless of the asymmetric market sizes because the net firm relocation effect is neutral in our model. The social planner imposes identical taxes in both countries to control emissions through the demand effect but does not adjust firm locations. Moreover, the tax rates can be negative $\left(t_{G O}=t_{G O}^{*}<0\right)$, which implies consumption subsidies. This case occurs when $\sigma$ is sufficiently small such that $\left.R H S\right|_{t=0}<1$. Intuitively, if $\sigma$ is sufficiently small, the varieties are very differentiated. Firms have stronger market power and tend to produce less. The social planner imposes consumption subsidies to encourage consumption and production. 
If $\sigma$ is sufficiently large, the varieties are close substitutes. Firms' market power weakens and they produce relatively more, which leads to more consumption emissions. In this case, the social planner imposes consumption taxes to control demand for dirty goods.

As shown in the new economic geography literature, without environmental issues, global welfare can increase as more firms are located in a larger country. In the current setting with consumption emissions, we also examine whether the social planner has an incentive to induce full agglomeration in Home. Since the firm relocation effect is neutral and emission targets can be realized by the demand effect, full agglomeration cannot be motivated by emission issues. In other words, even if full agglomeration occurs in Home, global emissions do not change. Since the emissions per unit of consumption are 1, the total consumption of dirty goods is the same. Therefore, capital rents and total tax revenue are the same in the two cases. Inducing full agglomeration in Home only reallocates tax revenue and consumption emissions across countries, but has no effect on their total levels. Denote the variables in the case of full agglomeration in Home with " $H$ " in the subscripts. We can obtain the following lemma. ${ }^{6}$

Lemma 3. In the two cases in which firms disperse across countries and fully agglomerate in Home, $(i) E_{G O}^{G}=E_{G O, H}^{G}$; $(i i) r_{G O}=r_{G O, H}$; and $(i i i) T R_{G O}+T R_{G O}^{*}=T R_{G O, H}+T R_{G O, H}^{*}$.

Therefore, whether the social planner has an incentive to induce full agglomeration depends only on the consumer surplus given the consumption of dirty goods. In other words, the question is how the social planner maximizes the total consumer surplus by distributing the firms (and thus the dirty goods) in the presence of asymmetric market sizes. The mass of firms affects the consumer surplus through changes in the aggregate price indices $\left(P\right.$ and $\left.P^{*}\right)$. When trade costs are high, that is, $s /(1-s)<\tau^{\sigma-1}, P^{*}$ would become too high and the consumer surplus in Foreign would become too low if firms fully agglomerate in Home. Therefore, the social planner always disperses firms.

Proposition 3. Optimal consumption taxes that maximize global welfare are neutral about firm location decisions. In particular, if firms disperse across countries under no environmental regulation, that is, $s /(1-s)<\tau^{\sigma-1}$, the consumption taxes (or subsidies) are identical regardless of market size.

\footnotetext{
${ }^{6}$ See Appendix A3 for the proofs of Lemma 3 and Proposition 3.
} 


\section{Discussion: Consumption Tax Competition}

This section discusses how to derive the Nash equilibrium in a two-stage game. In the first stage, countries simultaneously decide on the level of their consumption taxes. In the second stage, firms determine their location and production patterns in response to environmental regulations. In the main part of this paper, we investigated firm behavior under consumption tax. Here, we concentrate on the first stage of the game. For simplicity, we assume that $D\left(E^{W}\right)=\delta E^{W} .7$

Figure 2 describes the relationship between firm locations and environmental regulations, where $\zeta=s /(1+t)$ and $\zeta^{*}=(1-s) /\left(1+t^{*}\right)$ are defined as the market size-adjusted inverse consumption taxes in Home and Foreign. The coordinate system consists of three areas: in area $(i)$, full agglomeration occurs in Home; in area (iii), full agglomeration occurs in Foreign; and in area (ii), firms disperse across countries.

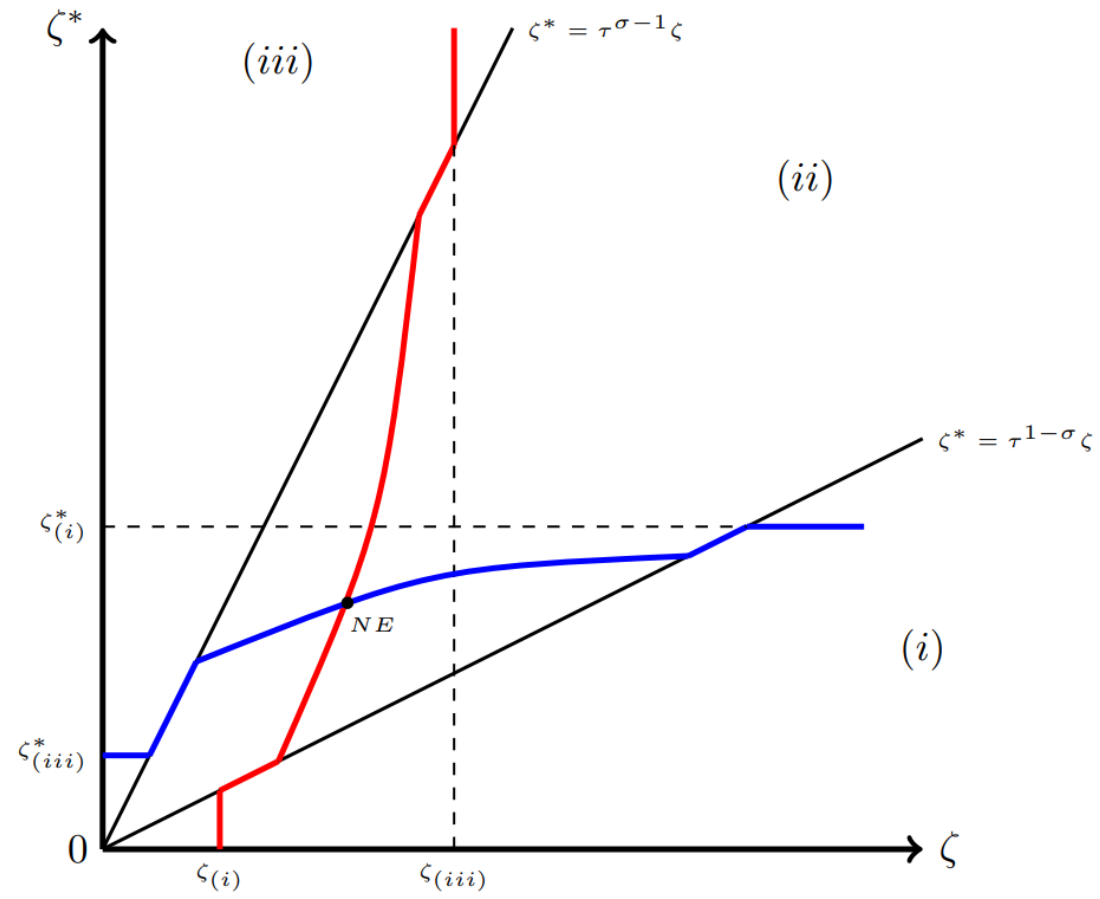

Figure 2: Nash equilibrium when $\sigma$ and $\tau$ are sufficiently large.

Denote Home welfare in each area as $W_{(i)}, W_{(i i)}$, and $W_{(i i i)}$, respectively. Foreign welfare still has asterisks. With endogenous location patterns, Home cannot always choose consumption taxes according to the first-order conditions with no constraint because location patterns may change among the three areas, in which case Home has to behave at the threshold values of taxes. Home

\footnotetext{
${ }^{7} \mathrm{~A}$ linear environmental damage function is often used in the analysis with endogenous firm locations. See, for example, Markusen et al. (1993, 1995) and Dong et al. (2012).
} 
then compares the welfare levels in the three areas to determine the optimal consumption tax with endogenous firm locations.

$$
\begin{aligned}
& \zeta_{B R}= \begin{cases}\zeta_{(i)}=\frac{1}{\frac{1}{s}-\frac{1}{\sigma}+\frac{\sigma-1}{\sigma} \delta} & \text { if } 0<\zeta^{*}<\zeta_{1}^{*} \\
\tau^{1-\sigma} \zeta^{*} & \text { if } \zeta_{1}^{*} \leq \zeta^{*}<\zeta_{2}^{*} \\
\frac{-\left(\beta \zeta^{*}-1\right)+\sqrt{\left(\beta \zeta^{*}-1\right)^{2}+4 \beta \frac{\sigma}{\sigma-1} \zeta^{*}}}{2 \beta} & \text { if } \zeta_{2}^{*} \leq \zeta^{*}<\zeta_{3}^{*}, \\
\tau^{\sigma-1} \zeta^{*} & \text { if } \zeta_{3}^{*} \leq \zeta^{*}<\zeta_{4}^{*} \\
\zeta_{(i i i)}=\frac{1}{\frac{1}{s}-\frac{1}{\sigma}+\frac{\sigma-1}{\sigma} \frac{\delta}{\tau}} & \text { if } \zeta^{*} \geq \zeta_{4}^{*}\end{cases} \\
& \text { where } \zeta_{1}^{*}=\tau^{1-\sigma} \zeta_{(i)}=\frac{\tau^{1-\sigma}}{\frac{1}{s}-\frac{1}{\sigma}+\frac{\sigma-1}{\sigma} \delta}, \quad \zeta_{2}^{*}=\frac{1+\frac{\sigma}{\sigma-1} \tau^{1-\sigma}}{\beta\left(1+\tau^{\sigma-1}\right)} \text {, } \\
& \zeta_{3}^{*}=\frac{1+\frac{\sigma}{\sigma-1} \tau^{\sigma-1}}{\beta\left(1+\tau^{1-\sigma}\right)}, \quad \zeta_{4}^{*}=\tau^{\sigma-1} \zeta_{(i i i)}=\frac{\tau^{\sigma-1}}{\frac{1}{s}-\frac{1}{\sigma}+\frac{\sigma-1}{\sigma} \frac{\delta}{\tau}}, \\
& \beta=\frac{1}{s}-\frac{1}{\sigma}+\frac{\sigma-1}{\sigma} \frac{\tau^{\sigma}+1}{\tau^{\sigma}+\tau} \delta .
\end{aligned}
$$

How Home responds to the Foreign consumption taxes depends on the relative strengths of the consumer surplus, capital rents, tax revenue, and environmental damage. The consumer surplus decreases in the Home consumption tax because the aggregate price of dirty goods in Home increases in its tax rates. Capital rents, derived as $r=Y /(\sigma-1)=\frac{\mu}{\sigma}\left(\frac{s}{1+t}+\frac{1-s}{1+t^{*}}\right)$, also decrease in $t$. However, tax revenue, $T R=\mu t /(1+t)$, always increases in $t$. In addition, as shown above, an increase in consumption tax decreases environmental damage.

When the Foreign consumption tax is high $\left(0<\zeta^{*}<\zeta_{2}^{*}\right)$, Home imposes consumption taxes so that firms fully agglomerate there. By doing so, Home benefits from a high consumer surplus and high capital rents, which dominate low tax revenue and high environmental damage. As the Foreign tax decreases $\left(\zeta_{2}^{*} \leq \zeta^{*}<\zeta_{3}^{*}\right)$, Home also decreases its tax to increase its consumer surplus. During this process, capital rents and environmental damage continue to increase, while tax revenue continues to decrease. When Foreign tax falls $\left(\zeta^{*} \geq \zeta_{3}^{*}\right)$, Home induces all firms to relocate to Foreign; otherwise, its tax revenue and environmental quality would be too low. For $\zeta_{2}^{*} \leq \zeta^{*}<\zeta_{3}^{*}$, Home responses are strategic complements to Foreign consumption taxes. An increase in Foreign consumption taxes drives Home's marginal loss below the marginal benefit from decreasing emissions, that is, $\frac{\mathrm{d}^{2}[(C S+r+T R)-D]}{\mathrm{d} \zeta \mathrm{d} \zeta^{*}}=\frac{\mu}{(\sigma-1)\left(\zeta+\zeta^{*}\right)^{2}}>0$; therefore, Home has an incentive to further decrease its emissions by increasing the consumption tax. 
Analogously, Foreign best responses are

$$
\begin{gathered}
\zeta_{B R}^{*}= \begin{cases}\zeta_{(i i i)}^{*}=\frac{1}{\frac{1}{1-s}-\frac{1}{\sigma}+\frac{\sigma-1}{\sigma} \delta} & \text { if } 0<\zeta<\zeta_{1} \\
\tau^{\sigma-1} \zeta & \text { if } \zeta_{1} \leq \zeta<\zeta_{2} \\
\frac{-\left(\beta^{*} \zeta-1\right)+\sqrt{\left(\beta^{*} \zeta-1\right)^{2}+4 \beta^{*} \frac{\sigma}{\sigma-1} \zeta}}{2 \beta^{*}} & \text { if } \zeta_{2} \leq \zeta<\zeta_{3}, \\
\tau^{1-\sigma} \zeta & \text { if } \zeta_{3} \leq \zeta<\zeta_{4} \\
\zeta_{(i)}^{*}=\frac{1}{\frac{1}{1-s}-\frac{1}{\sigma}+\frac{\sigma-1}{\sigma} \frac{\delta}{\tau}} & \text { if } \zeta \geq \zeta_{4}\end{cases} \\
\text { where } \zeta_{1}=\tau^{1-\sigma} \zeta_{(i i i)}^{*}=\frac{\tau^{1-\sigma}}{\frac{1}{1-s}-\frac{1}{\sigma}+\frac{\sigma-1}{\sigma} \delta}, \quad \zeta_{2}=\frac{1+\frac{\sigma}{\sigma-1} \tau^{1-\sigma}}{\beta^{*}\left(1+\tau^{\sigma-1}\right)},
\end{gathered}
$$

The intuition behind Foreign best responses is the same as Home. Generally, as Home consumption taxes increase, Foreign also increases its consumption taxes because of the relative strengths between the consumer surplus, capital rents, tax revenue, and environmental damage. Correspondingly, location patterns shift from full agglomeration in Home to dispersion across countries and eventually to full agglomeration in Foreign. Figure 2 shows the reaction curves of Home (denoted by red curves) and Foreign (denoted by blue curves). As long as $\sigma$ and $\tau$ are sufficiently high, a unique Nash equilibrium always exists in which firms disperse across countries. ${ }^{8}$

The consumption taxes at the equilibrium are derived as

$$
\begin{aligned}
& t_{N E}=\frac{2\left(\beta \beta^{*}-\beta^{2}\right) s}{\beta^{*}-\frac{3 \sigma-1}{\sigma-1} \beta+\sqrt{\left(\beta^{*}-\beta\right)^{2}+\frac{4 \sigma^{2}}{(\sigma-1)^{2}} \beta \beta^{*}}}-1 ; \\
& t_{N E}^{*}=\frac{2\left(\beta^{* 2}-\beta \beta^{*}\right)(1-s)}{\frac{3 \sigma-1}{\sigma-1} \beta^{*}-\beta-\sqrt{\left(\beta^{*}-\beta\right)^{2}+\frac{4 \sigma^{2}}{(\sigma-1)^{2}} \beta \beta^{*}}}-1 ;
\end{aligned}
$$

which are strongly dependent on the market size of each country. If the market sizes are identical, $\beta=\beta^{*}$ holds, leading to the equalization of consumption taxes across countries, that is, $t_{N E}=$ $t_{N E}^{*}=\frac{2 \beta s(\sigma-1)}{2 \sigma-1}-1$. However, if the market sizes are asymmetric, the advantage of a larger market size encourages Home to impose a higher consumption tax or a lower consumption subsidy than

\footnotetext{
${ }^{8} \sigma$ and $\tau$ are sufficiently large so that $T_{3}^{*}<T_{4}^{*}$ and $T_{3}<T_{4}$ hold. Otherwise, the reaction curves of Home and Foreign when firms disperse would expand outward, in which case the model becomes intractable.
} 
Foreign, that is, $t_{N E}>t_{N E}^{*}{ }^{9}$

\section{Conclusion}

In this study, we extended the footloose capital model to answer several ongoing questions in the literature on trade and the environment under consumption pollution. Specifically, we explored how trade liberalization and consumption taxes affect firm locations, consumption and GHG emissions and how countries decide on their consumption taxes cooperatively and non-cooperatively in the presence of monopolistic competition, endogenous firm locations, and asymmetric market sizes. We found that when firms disperse across countries, an increase in a country's consumption tax drives firms to move to the other country. However, how trade liberalization affects firm location patterns is ambiguous and depends on the tension between consumption tax and market size. If the market size is sufficiently large, firms may relocate to the country with more stringent consumption taxes. Trade liberalization can decrease GHG emissions initially and subsequently increase them. An increase in a country's consumption tax always decreases its own and global emissions, while increasing the emissions of other countries. In the global optimum, the social planner imposes identical consumption taxes across countries to maximize global welfare if firms disperse across countries under no environmental regulation. Firm locations are unchanged. Under consumption tax competition, if the elasticities of substitution among different varieties and trade costs are sufficiently high, a Nash equilibrium exists in which firms disperse across countries and the consumption tax is higher in the larger country.

Finally, we emphasize two potential extensions of this study. As an essential source of consumption pollution, gasoline is always at the center of this issue. Gasoline is crucial not only because its consumption is massive, but also because changes in its price have been demonstrated to be an important channel of carbon leakage (e.g., Kiyono and Ishikawa, 2013). Further analysis should be performed to study how policymakers design policies to control GHG emissions with the existence of carbon leakage stemming from the price changes of natural resources. The other issue is the choice of firms between abatement investment and FDI. If environmental regulation is not stringent compared with abatement costs, firms may prefer to pay for their emissions. However, if environmental regulation is strict but not as strict as the costs of FDI, firms may abate their emissions by investing in expensive equipment and machines. If environmental regulation is sufficiently stringent, firms may choose FDI instead of investing in abatement. Such endogenous choices are important, especially when firms have different productivity levels, mobility, emission intensities, and abatement technologies.

\footnotetext{
${ }^{9}$ See Appendix A4.
} 


\section{References}

Antweiler, W., Copeland, B. R., and Taylor, M. S. (2001). Is free trade good for the environment? American Economic Review, 91(4):877-908.

Baldwin, R. E. and Krugman, P. (2004). Agglomeration, integration and tax harmonisation. European Economic Review, 48(1):1-23.

Cheng, H., Kato, H., and Obashi, A. (2020). Is environmental tax harmonization desirable in global value chains? The B.E. Journal of Economic Analysis 6 Policy, 1(ahead-of-print).

Copeland, B. R. and Taylor, M. S. (1994). North-south trade and the environment. Quarterly Journal of Economics, 109(3):755-787.

Copeland, B. R. and Taylor, M. S. (1995a). Trade and the environment: a partial synthesis. American Journal of Agricultural Economics, 77(3):765-771.

Copeland, B. R. and Taylor, M. S. (1995b). Trade and transboundary pollution. American Economic Review, $85(4): 716-737$.

Cremer, H. and Gahvari, F. (2004). Environmental taxation, tax competition, and harmonization. Journal of Urban Economics, 55(1):21-45.

Davis, S. J. and Caldeira, K. (2010). Consumption-based accounting of $\mathrm{CO}_{2}$ emissions. Proceedings of the National Academy of Sciences, 107(12):5687-5692.

Dixit, A. K. and Stiglitz, J. E. (1977). Monopolistic competition and optimum product diversity. American Economic Review, 67(3):297-308.

Dong, B., Gong, J., and Zhao, X. (2012). FDI and environmental regulation: pollution haven or a race to the top? Journal of Regulatory Economics, 41(2):216-237.

Druckman, A., Bradley, P., Papathanasopoulou, E., and Jackson, T. (2008). Measuring progress towards carbon reduction in the uk. Ecological Economics, 66(4):594-604.

Haufler, A. and Pflüger, M. (2004). International commodity taxation under monopolistic competition. Journal of Public Economic Theory, 6(3):445-470.

Haufler, A. and Wooton, I. (2010). Competition for firms in an oligopolistic industry: The impact of economic integration. Journal of International Economics, 80(2):239-248.

Hoel, M. (1997). Environmental policy with endogenous plant locations. Scandinavian Journal of Economics, 99(2):241-259.

$\mathrm{Hu}$, B. and McKitrick, R. (2016). Decomposing the environmental effects of trade liberalization: The case of consumption-generated pollution. Environmental and Resource Economics, 64(2):205-223.

Ishikawa, J. and Kuroda, T. (2007). How effective are emissions taxes in an open economy? Review of Development Economics, 11(2):359-368.

Ishikawa, J. and Okubo, T. (2010). Environmental and trade policies for oligopolistic industry in the presence of consumption externalities. International Economy, 2010(14):59-76.

Ishikawa, J. and Okubo, T. (2011). Environmental product standards in north-south trade. Review of Development Economics, 15(3):458-473.

Ishikawa, J. and Okubo, T. (2016). Greenhouse-gas emission controls and international carbon leakage through trade liberalization. International Economy, 19:1-22.

Ishikawa, J. and Okubo, T. (2017). Greenhouse-gas emission controls and firm locations in north-south trade. Environmental and Resource Economics, 67(4):637-660. 
Kiyono, K. and Ishikawa, J. (2013). Environmental management policy under international carbon leakage. International Economic Review, 54(3):1057-1083.

Krutilla, K. (1991). Environmental regulation in an open economy. Journal of Environmental Economics and Management, 20(2):127-142.

Ludema, R. D. and Wooton, I. (2000). Economic geography and the fiscal effects of regional integration. Journal of International Economics, 52(2):331-357.

Markusen, J. R., Morey, E. R., and Olewiler, N. D. (1993). Environmental policy when market structure and plant locations are endogenous. Journal of Environmental Economics and Management, 24(1):69-86.

Markusen, J. R., Morey, E. R., and Olewiler, N. D. (1995). Competition in regional environmental policies when plant locations are endogenous. Journal of Public Economics, 56(1):55-77.

Martin, P. and Rogers, C. A. (1995). Industrial location and public infrastructure. Journal of International Economics, 39(3-4):335-351.

Rauscher, M. (1995). Environmental regulation and the location of polluting industries. International Tax and Public Finance, 2(2):229-244.

Vlassis, N. (2013). The welfare consequences of pollution-tax harmonization. Environmental and Resource Economics, $56(2): 227-238$.

Wiedmann, T. (2009). A review of recent multi-region input-output models used for consumption-based emission and resource accounting. Ecological Economics, 69(2):211-222.

Zeng, D.-Z. and Zhao, L. (2009). Pollution havens and industrial agglomeration. Journal of Environmental Economics and Management, 58(2):141-153. 


\section{Appendix}

\section{A1. Consumption and Emissions under Full Agglomeration.}

For $\frac{1+t}{1+t^{*}} \leq \frac{s}{1-s} \tau^{1-\sigma}$, all firms agglomerate in Home, Foreign specializes in the production of the clean good, and Foreign imports the dirty goods from Home. In this case, $n=1, n^{*}=0$; $x^{H H}=\frac{\mu(\sigma-1)}{\sigma} \frac{1}{1+t}, x^{H F}=\frac{\mu(\sigma-1)}{\sigma} \frac{1}{\tau\left(1+t^{*}\right)}, x^{F H}=x^{F F}=0 ; E=\frac{\mu(\sigma-1)}{\sigma} \frac{s}{1+t}, E^{*}=\frac{\mu(\sigma-1)}{\sigma} \frac{1-s}{\tau\left(1+t^{*}\right)}$ and $E^{G}=\frac{\mu(\sigma-1)}{\sigma}\left[\frac{s}{1+t}+\frac{1-s}{\tau\left(1+t^{*}\right)}\right]$. For $\frac{1+t}{1+t^{*}} \geq \frac{s}{1-s} \tau^{\sigma-1}$, all firms agglomerate in Foreign, Home specializes in the production of the clean good, and Home imports the dirty goods from Foreign. In this case, $n=0, n^{*}=1 ; x^{F F}=\frac{\mu(\sigma-1)}{\sigma} \frac{1}{1+t^{*}}, x^{F H}=\frac{\mu(\sigma-1)}{\sigma} \frac{1}{\tau(1+t)}, x^{H H}=x^{H F}=0 ; E^{*}=$ $\frac{\mu(\sigma-1)}{\sigma} \frac{1-s}{1+t^{*}}, E=\frac{\mu(\sigma-1)}{\sigma} \frac{s}{\tau(1+t)}$ and $E^{G}=\frac{\mu(\sigma-1)}{\sigma}\left[\frac{1-s}{1+t^{*}}+\frac{s}{\tau(1+t)}\right]$.

\section{A2. Proof of Proposition 1.}

Consider a case where $(1+t) /\left(1+t^{*}\right)=s /(1-s)$ so that consumption taxes do not affect firm locations. Differentiating global GHG emissions in trade with footloose capital with respect to $\tau$ gives

$$
\frac{\mathrm{d} E^{G}}{\mathrm{~d} \tau}=\frac{\mu(\sigma-1)}{\sigma}\left(\frac{s}{1+t}+\frac{1-s}{1+t^{*}}\right) \frac{(\sigma-1) \tau^{\sigma}-\sigma \tau^{\sigma-1}-1}{\left(\tau^{\sigma}+\tau\right)^{2}}
$$

$\frac{\mathrm{d}\left[(\sigma-1) \tau^{\sigma}-\sigma \tau^{\sigma-1}-1\right]}{\mathrm{d} \tau}=\sigma(\sigma-1) \tau^{\sigma-2}(\tau-1)>0$ always holds, therefore, $(\sigma-1) \tau^{\sigma}-\sigma \tau^{\sigma-1}-1$ is an increasing function of $\tau$ for $\tau>1$. When $\tau=1$, the polynomial is -2 ; when $\tau=\frac{\sigma+1}{\sigma-1}$, the polynomial is equal to $\tau^{\sigma-1}-1>0$. Thus, $\frac{\mathrm{d} E^{G}}{\mathrm{~d} \tau}=0$ exists for $1<\tau<\frac{\sigma+1}{\sigma-1}$. Denote the certain point as $\tau_{0}$, then $E^{G}$ decreases for $1<\tau<\tau_{0}$ and increases for $\tau>\tau_{0}$. In other words, as trade costs decline from infinity to unity, global GHG emissions initially decrease and then increase.

\section{A3. Global Optimum}

\section{Global Optimum: Firms Disperse}

Define global welfare as the sum of individual welfare around the world:

$$
W^{G}=s U+(1-s) U^{*}
$$


where

$$
\begin{aligned}
U= & \mu \ln M+I / s-\mu-D\left(E^{G}\right) \\
= & \mu \ln \mu-\mu \ln P+1+r+T R / s-\mu-D\left(E^{G}\right) \\
= & \mu \ln \mu-\left\{\mu \ln \left(\frac{\sigma}{\sigma-1}\right)-\frac{\mu}{\sigma-1} \ln \left(1+\tau^{1-\sigma}\right)+\mu \ln (1+t)+\frac{\mu}{\sigma-1} \ln \left(1+\frac{1-s}{s} \frac{1+t}{1+t^{*}}\right)\right\}+1 \\
& +\frac{\mu}{\sigma}\left(\frac{s}{1+t}+\frac{1-s}{1+t^{*}}\right)+\mu \frac{t}{1+t}-\mu-D\left(E^{G}\right) .
\end{aligned}
$$

and

$$
\begin{aligned}
U^{*}= & \mu \ln \mu-\mu \ln \left(\frac{\sigma}{\sigma-1}\right)+\frac{\mu}{\sigma-1} \ln \left(1+\tau^{1-\sigma}\right)-\mu \ln \left(1+t^{*}\right)-\frac{\mu}{\sigma-1} \ln \left(1+\frac{s}{1-s} \frac{1+t^{*}}{1+t}\right)+1 \\
& +\frac{\mu}{\sigma}\left(\frac{1-s}{1+t^{*}}+\frac{s}{1+t}\right)+\mu \frac{t^{*}}{1+t^{*}}-\mu-D\left(E^{G}\right) .
\end{aligned}
$$

Remind that for $s /(1-s)<\tau^{\sigma-1}$,

$$
1+t_{G O}=\frac{\sigma-1}{\sigma}+\frac{\sigma-1}{\sigma} \frac{\tau^{\sigma}+1}{\tau^{\sigma}+\tau} D^{\prime}\left(E^{G}\right)
$$

global emissions at the social optimum are determined by

$$
E_{G O}^{G}=\frac{\mu\left(1+\tau^{\sigma}\right)}{\tau^{\sigma}+\tau+\left(1+\tau^{\sigma}\right) D^{\prime}\left(E_{G O}^{G}\right)} .
$$

\section{Global Optimum: Full Agglomeration in Home}

If the social planner induces full agglomeration in Home, global welfare becomes

$$
\begin{aligned}
W_{H}^{G}= & W_{H, H}+W_{H, F}=\mu \ln \mu-\mu \ln \left(\frac{\sigma}{\sigma-1}\right)-\mu(1-s) \ln \tau+1-\mu s \ln (1+t)-\mu(1-s) \ln \left(1+t^{*}\right) \\
& -\frac{\mu(\sigma-1)}{\sigma}\left(\frac{s}{1+t}+\frac{1-s}{1+t^{*}}\right)-D\left(E_{H}^{G}\right) .
\end{aligned}
$$

$W_{H, H}$ and $W_{H, F}$ denote Home and Foreign welfare as follows:

$$
\begin{gathered}
W_{H, H}=\mu \ln \mu-\mu \ln \left(\frac{\sigma}{\sigma-1}\right)-\mu \ln (1+t)+1+\frac{\mu}{\sigma}\left(\frac{s}{1+t}+\frac{1-s}{1+t^{*}}\right)+\mu \frac{t}{1+t}-\mu-D\left(E_{H}^{G}\right) ; \\
W_{H, F}=\mu \ln \mu-\mu \ln \left(\frac{\sigma}{\sigma-1}\right)-\mu \ln \left(1+t^{*}\right)-\mu \ln \tau+1+\frac{\mu}{\sigma}\left(\frac{s}{1+t}+\frac{1-s}{1+t^{*}}\right)+\mu \frac{t^{*}}{1+t^{*}}-\mu-D\left(E_{H}^{G}\right) .
\end{gathered}
$$


Solving the first-order conditions with respect to $t$ and $t^{*}$ gives

$$
t=\frac{(\sigma-1)\left(1+D^{\prime}\right)}{\sigma}-1 ; \quad t^{*}=\frac{\sigma-1}{\sigma}\left(1+\frac{D^{\prime}}{\tau}\right)-1 .
$$

Note that

$$
\frac{1+t}{1+t^{*}}=\frac{\tau\left(1+D^{\prime}\right)}{\tau+D^{\prime}}>1>\frac{s}{1-s} \tau^{1-\sigma} .
$$

The taxes are not available because full agglomeration in Home never happens if the consumption taxes are imposed. So the social planner acts at the threshold value where $\frac{1+t}{1+t^{*}}=\frac{s}{1-s} \tau^{1-\sigma}$.

\section{Proof of Lemma 3}

Taking $\frac{1+t}{1+t^{*}}=\frac{s}{1-s} \tau^{1-\sigma}$ into $W_{H}^{G}$ and solving the welfare maximization problem give

$$
1+t_{G O, H}=\frac{s(\sigma-1)}{\sigma}\left(1+\tau^{1-\sigma}+\frac{1+\tau^{\sigma}}{\tau^{\sigma}} D^{\prime}\left(E_{H}^{G}\right)\right)
$$

Hence, global emissions at the global optimum when full agglomeration occurs in Home are

$$
E_{G O, H}^{G}=\frac{\mu\left(1+\tau^{\sigma}\right)}{\tau^{\sigma}+\tau+\left(1+\tau^{\sigma}\right) D^{\prime}\left(E_{G O, H}^{G}\right)},
$$

which takes the same form as $E_{G O}^{W}$. For both $E_{G O}^{G}$ and $E_{G O, H}^{G}$, their left hand sides increase in global emissions and their right hand sides decrease in global emissions (i.e., $D^{\prime \prime}>0$ ). There exists only one solution for the equation, which implies that $E_{G O}^{G}=E_{G O, H}^{G}$ as shown in Figure A.1.

With $\frac{1+t}{1+t^{*}}=\frac{s}{1-s} \tau^{1-\sigma}$ and $E_{G O}^{G}=E_{G O, H}^{G}$, we can get the optimal consumption taxes when firms fully agglomeration in Home.

$$
t_{G O, H}=s\left(1+\tau^{1-\sigma}\right)\left(1+t_{G O}\right)-1 ; \quad t_{G O, H}^{*}=(1-s)\left(1+\tau^{\sigma-1}\right)\left(1+t_{G O}\right)-1 .
$$

Note that

$$
\frac{s}{1+t_{G O}}+\frac{1-s}{1+t_{G O}^{*}}=\frac{s}{1+t_{G O, H}}+\frac{1-s}{1+t_{G O, H}^{*}} .
$$

Therefore, capital rents $r=\frac{\mu}{\sigma}\left(\frac{s}{1+t}+\frac{1-s}{1+t^{*}}\right)$ and total tax revenue $T R+T R^{*}=\frac{\mu t}{1+t}+\frac{\mu t^{*}}{1+t^{*}}$ are the same in the two cases. 




Figure A.1: $E_{G O}^{G}=E_{G O, H}^{G}$ must hold.

\section{Proof of Proposition 3}

For $s /(1-s)<\tau^{\sigma-1}$, the difference between global welfare in the two cases is

$$
\begin{gathered}
\left.W_{G O}^{G}-W_{G O, H}^{G}=\frac{\mu \sigma}{\sigma-1}\left[s \ln s+(1-s) \ln (1-s)+\ln \left(1+\tau^{1-\sigma}\right)+(1-s)(\sigma-1) \ln \tau\right)\right] . \\
\frac{\mathrm{d}\left(W_{G O}^{G}-W_{G O, H}^{G}\right)}{\mathrm{d} \tau}=0 \Longrightarrow \tau^{\sigma-1}=\frac{s}{1-s} . \\
W_{G O}^{G}-W_{G O, H}^{G}>\left.\left(W_{G O}^{G}-W_{G O, H}^{G}\right)\right|_{\tau^{\sigma-1}=\frac{s}{1-s}}=0 .
\end{gathered}
$$

Therefore, the social planner never has an incentive to induce full agglomeration in Home.

In the case where $s /(1-s) \geq \tau^{\sigma-1}$ holds, firms fully agglomerate in Home when there is no environmental regulation. The social planner has no incentive to make firms disperse across countries because trade costs are low. Consequently, $P^{*}$ would not be so high under full agglomeration in Home. The increase in Home consumer surplus due to a lower $P$ can dominate the decrease in Foreign consumer surplus due to a higher $P^{*}$. Hence, the social planner maintains full agglomeration in Home and sets a higher consumption tax in Home than in Foreign.

Firm locations remain unchanged in the two cases of dispersion and full agglomeration. 


\section{A4. Consumption Tax Competition}

\section{Comparison of Consumption Taxes at the Nash Equilibrium}

We compare $t_{N E}$ and $t_{N E}^{*}$ as follows:

$$
\frac{1+t_{N E}}{1+t_{N E}^{*}}=\frac{\beta s}{\beta^{*}(1-s)} \frac{\frac{3 \sigma-1}{\sigma-1} \beta^{*}-\beta-\sqrt{\left(\beta^{*}-\beta\right)^{2}+\frac{4 \sigma^{2}}{(\sigma-1)^{2}} \beta \beta^{*}}}{\beta^{*}-\frac{3 \sigma-1}{\sigma-1} \beta+\sqrt{\left(\beta^{*}-\beta\right)^{2}+\frac{4 \sigma^{2}}{(\sigma-1)^{2}} \beta \beta^{*}}}
$$

where $\beta^{*}=\frac{2 s-1}{s(1-s)}+\beta$.

Because $\sigma$ and $\tau$ are sufficiently large, $\beta>1 / s$ holds. Therefore,

$$
\frac{\beta s}{\beta^{*}(1-s)}=\frac{\beta s}{\frac{2 s-1}{s}+\beta(1-s)}=\frac{1}{\frac{2 s-1}{\beta s^{2}}+\frac{1-s}{s}}>1 .
$$

Moreover,

$$
\begin{aligned}
& \frac{3 \sigma-1}{\sigma-1} \beta^{*}-\beta-\sqrt{\left(\beta^{*}-\beta\right)^{2}+\frac{4 \sigma^{2}}{(\sigma-1)^{2}} \beta \beta^{*}}-\left\{\beta^{*}-\frac{3 \sigma-1}{\sigma-1} \beta+\sqrt{\left(\beta^{*}-\beta\right)^{2}+\frac{4 \sigma^{2}}{(\sigma-1)^{2}} \beta \beta^{*}}\right\} \\
& =\frac{2 \sigma}{\sigma-1} \beta^{*}+\frac{2 \sigma}{\sigma-1} \beta-2 \sqrt{\left(\beta^{*}-\beta\right)^{2}+\frac{4 \sigma^{2}}{(\sigma-1)^{2}} \beta \beta^{*}}>0
\end{aligned}
$$

because

$$
\left(\frac{2 \sigma}{\sigma-1} \beta^{*}+\frac{2 \sigma}{\sigma-1} \beta\right)^{2}-\left(2 \sqrt{\left(\beta^{*}-\beta\right)^{2}+\frac{4 \sigma^{2}}{(\sigma-1)^{2}} \beta \beta^{*}}\right)^{2}=\frac{4(2 \sigma-1)}{(\sigma-1)^{2}}\left(\beta^{*}-\beta\right)^{2}>0 .
$$

As a result,

$$
\frac{\frac{3 \sigma-1}{\sigma-1} \beta^{*}-\beta-\sqrt{\left(\beta^{*}-\beta\right)^{2}+\frac{4 \sigma^{2}}{(\sigma-1)^{2}} \beta \beta^{*}}}{\beta^{*}-\frac{3 \sigma-1}{\sigma-1} \beta+\sqrt{\left(\beta^{*}-\beta\right)^{2}+\frac{4 \sigma^{2}}{(\sigma-1)^{2}} \beta \beta^{*}}}>1 .
$$

Therefore, $\frac{1+t_{N E}}{1+t_{N E}^{*}}>1$ stands, implying that $t_{N E}>t_{N E}^{*}$. 